\title{
Race equality, human rights and mental health legislation: Recent developments in England and Wales
}

England now has revised mental health legislation following the passage of a mental health Bill through both Houses of Parliament following protracted discussions over seven years. The Mental Health Bill 2006, amending the Mental Health Act 1983, eventually received Royal Assent on 19 July 2007. There is much that could be said about the new Act, which makes a number of important changes to the present legislation. These changes include a new single definition of mental disorder; the abolition of the so-called 'treatability test'; and the extension of compulsion into the community through a supervised community treatment order.

However, we wish to focus on a previously little discussed issue that is now engaging many commentators in the UK: the disproportionate admission and detention of black and minority ethnic patients in mental hospitals, ${ }^{1,2}$ and the lack of sufficient attention to this matter during the preparatory phases of the new Act.

The UK has relatively progressive race relations legislation, but it is not always followed as assiduously as it should be. For example, the Race Relations (Amendment) Act 2000 places positive duties on most public authorities that require them to have due regard to the need to eliminate unlawful discrimination, promote equality of opportunity and promote good relations between people of different racial groups.

In order to fulfil the General Duty public authorities must, among other actions, undertake Race Equality Impact Assessments (REIAs) of all new policies and functions. The purpose of these assessments is to ensure the authority meets the three elements of the general duty. These three elements define a new imperative for public bodies' assessment of their policies, especially the positive duties to promote equality of opportunity and good race relations. Any REIA must demonstrate the way in which the public authority will go beyond a limited assessment of the (negative) impact of the policy towards positive action to achieve improvements in the effect of the policies.

During the preparation of the Mental Health Bill, both the REIA process and outcome were contentious, especially within black and minority ethnic communities. A previous draft Bill, that had taken five years to prepare, was dropped, and a shorter Bill adopted in its place. Because there had been extensive debate on the earlier Bill, the government truncated debate on the revised Bill even though there remained considerable disquiet about the Bill's implications. A somewhat watered down REIA process was adopted; but although the full implications of the Bill on BME groups were not explored the government went ahead with the legislation. The resultant Mental Health Act 2007 amends the Mental Health Act 1983 in a number of specific and important ways. ${ }^{3}$

\section{Race Equality Impact Assessment}

The REIA process adopted by the Department of Health (DH) incorporated three elements: a series of stakeholder conferences or consultation meetings at various venues around the country; the establishment of an ad hoc advisory group chaired by one of the authors (Patel of Bradford); and a collaborative exercise by the Department of Health and some advisors. The aim of these was to analyse the impact on black and minority ethnic groups of the amendments to the patient pathway as determined by sections of the Act. By identifying the direct and indirect links between the proposed amendments and other parts of the Act, and by looking closely at relevant research on the operation of the Act with minority groups, it was possible to gain some understanding of the likely impact of the amendments on black and minority ethnic service users. * The result was a report issued by the $\mathrm{DH}^{4}{ }^{4}$ which represented an initial assessment based on expert knowledge; but it was neither a consensus view of the stakeholders involved nor a formal systematic review.

Five of the seven key amendments were thought likely by BME groups to have effects that would extend well beyond the immediate application of the amendment: ${ }^{\dagger}$ Each was considered likely to have an impact on the patient pathway, and liable to have a differential impact on black and minority ethnic patients because of their higher admission and detention rates. It was difficult to be precise about the impact of the amendments on black and minority ethnic groups as the research evidence is inconclusive and contentious. ${ }^{5,6}$ However, there were two particular ways

\footnotetext{
*An 'analysis tree' developed by a sub-group of the Advisory Group demonstrated the necessary links between the amendments and other sections of the Act, the core of which was the legal (i.e. the sections of the Act) 'pathway' to being detained using the proposed supervised community treatment (SCT) arrangements - in essence a pathway from first admission to eventual discharge. Any disparity by race or ethnicity in the use of these linked sections could affect the pathway and the proportions of patients considered for SCT.

${ }^{\dagger}$ The five were:

- Having a single definition of mental disorder

- Amending the 'treatability' test to one of 'appropriate treatment is available'

- Removing the exclusions that minimise the likelihood of a person being detained solely as a

result of, for example, drug or alcohol abuse

- Establishing a form of 'supervised community treatment' (SCT) as a replacement to section 25A IAfter Care Under Supervision]

- Widening the range of professional staff that can be considered clinical supervisors for the purposes of detention
} 
in which it was thought there might be disproportionate effects. First, widening the definition of mental disorder for the purposes of detention might interact with the greater likelihood of diagnosis of mental disorder in these groups to create a heightened likelihood of detention for black and minority ethnic patients; and second, most of these groups (with some notable exceptions, especially Chinese and Indian groups) have substantially higher rates of admission and detention than average.

These higher admission and detention ratios were thought likely to flow through the 'detention pathway' and lead to one of two outcomes, both detrimental to black and minority ethnic patients; either the higher proportion of inpatients would translate into a higher likelihood of being discharged on the new community treatment order (CTO) arrangements, with potentially detrimental effects on society's perception of mentally disordered people in those groups; or paradoxically, the heightened risk aversion encouraged by the Bill would lead to a reluctance to discharge even on a CTO (the efficacy of which is in any case not yet proven ${ }^{\ddagger}$ ) and have the effect of increasing even further the proportion of black and minority ethnic service users who are inpatients at any time.

\section{Achieving radical change: Delivering race equality in mental health care}

Experience of the REIA process used suggests that it was insufficient to tackle the conceptual shifts needed if mental health law is to be genuinely effective for all those to whom it may apply, especially black and minority ethnic groups. Much more needs to be done by governments to understand the impact of current and proposed legislation on black and minority ethnic groups. In England and Wales the UK government already has a well-crafted action plan (Delivering Race Equality in mental health care - known as DRE), ${ }^{7}$ which has been effective so far, but now demands greater resources for implementation, and a commitment to addressing the issues raised here. While DRE has been successful so far, a more radical approach is needed in the UK because the changes in the amending Act may operate to increase the number of patients detained, and to do so disproportionately given that black and minority ethnic patients are already subject to significantly higher rates of admission and detention than white patients (between 2 times and 14 times), ${ }^{8}$ for reasons that are unclear.

A fundamental and radical review is required of the way mental health legislation impacts upon and services interact with black and minority ethnic communities. If current legislation is, for whatever reason, perceived by black and minority ethnic

${ }^{\ddagger}$ See the report of the debates in the House of Lords Committee stages of the Bill: Hansard 8, 10,15 and 17 January 2007. communities in England and Wales as discriminatory, and the effects are even to some degree as described, then a radical reinterpretation of the form and function of legislation may be required. This cannot be done quickly or easily, and will demand an in-depth process of consultation and engagement of black and minority ethnic communities.

Mental health legislation is inherently discriminatory in practice. This is not its intent, nor is it suggested that the England and Wales Act was drafted with the express purpose of discriminating against black and minority ethnic communities. The Act operates disproportionately for many reasons, some of which are well understood and some of which remain at present obscure. In contrast to recent arguments ${ }^{6}$ some of this is undoubtedly the result of institutional discrimination. The Act reflects community norms, which inter alia include institutionally racist elements and attitudes. These combine with the discriminatory formulation of the law to reinforce both stereotypical approaches to patients and (usually unintended) discriminatory practice.

One reason the England and Wales Act operates the way it does is that it is conceptually 'negative' - that is, it is based on compulsory deprivation of liberty of the individual as a response to psychological distress. Unlike the legislation of some other countries, British legislation tends to be individualistic and reductive. An assessment of mental disorder incorporates a range of factors into the aetiology of the patient's condition rather than recognising the patient's condition as, in part, an expression of the various deprivations in the community - economic, social, familial and psychological. Instead of focusing resources for ameliorating the conditions within which mental disorder emerges, resources are applied reductively to the individual expression of the communities' distress.

This is not to say that individuals do not suffer illness, or that they do not have the right to appropriate care for their mental disorder. Rather, an alternative formulation of legislation would incorporate rights to assessments and services, and 'positive' clauses or duties that demand services outreach into the community and engage minority groups so that they can jointly identify the conditions that create the experience of distress. Such a positive duty would result in effective actions to provide social, psychological, familial and economic support to individuals, their families and the wider community. Similarly legislation should promote and encourage, if not actually require, research into the reasons for the higher levels of diagnosis of psychosis in black groups especially on whether Eurocentric diagnostic classifications are appropriate to people with markedly different cultural backgrounds and expectations

The Race Relations (Amendment) Act 2000 is an example of legislation that seeks to address institutional barriers to equality, by requiring public authorities to have in place strategies for 
combating race inequality, and by placing a statutory duty on government to undertake the type of REIA that is the subject of this discussion. A 'positive' approach would be to undertake something akin to the REIA at the beginning, as well as at the end of the process of policy development and legislative drafting. In that way the preparatory process might build on perceived problems with the operation of existing legislation, rather than obtaining comment post hoc from the REIA consultation. This demands a paradigm shift of attitude within government departments and public authorities to be open to the possibility of significant change to reflect emerging understanding of differential impact of policy on black and minority ethnic groups as a result of these analyses.

Ideally legislation should enshrine a duty on appropriate local and national authorities, including mental health service commissioners and providers, to engage black and minority ethnic communities in commissioning services that are appropriate to the needs of those communities, and to identify ways in which psychiatric assessment can be made relevant to the culture and values of those communities. A valuable outcome of the REIA would be an agreed process for reviewing the operation of the Act at intervals to identify reasons for differential or disproportionate and inappropriate admissions, and to make the necessary remedial adjustments to legislation.

\section{Summary}

In summary we suggest that three inter-related responses are needed to the current situation.

First, governments must seek to understand and accept more fully the way that mental health legislation operates differentially because different groups are different, with different rates of diagnosis or rates of illness, different causes of illness, possibly different illnesses (albeit given the same 'labels'), and different interactions with mental health and allied services. This demands action to achieve equity in relation to need in the availability of mental health services and especially in the use of compulsion.

Second, the advantage of a race equality impact assessment is evident; all governments should be encouraged to have similar statutes and to ensure they are implemented. In so doing jurisdictions would be more likely to develop workable, acceptable and appropriate legislation for the 21 st century. Legislation could then have carefully stated objectives rooted in community but with a concern primarily for the individual patient, and encourage innovative, flexible and equitable care, above all recognising diversity and the differential impact of present legislative construction

Third, governments should be encouraged to review the inherent discrimination against minority ethnic communities often found in mental health legislation and identify 'positive' alternative formulations that engage those communities. To make this effective, governments should consider building duties into the legislation that require public health and social care authorities to engage minority ethnic communities in making mental health services relevant and appropriate to the communities served.

\section{Lord Patel of Bradford}

Head of the Centre for Ethnicity and Health

UK

\section{Chris Heginbotham}

Co-Director of the Institute for Philosphy, Diversity and Mental Health

University of Central Lancashire

Preston, PRI 2AE

UK

1. NIMHE (National Institute for Mental Health in England). Inside Outside: Improving Mental Health Services for Black and Minority Ethnic Communities in England. London: Department of Health, 2003

2. Sainsbury Centre for Mental Health. Breaking the Circles of Fear. London: SCMH, 2002

3. Mental Health Act Commission. Count Me In: The Results of a Service User Survey. Nottingham: Mental Health Act Commission, 2006.

4. Department of Health. Mental Health Bill 2006: Race Equality Impact Assessment. London: Department of Health, 2006.

5. Harrison G. Ethnic minorities and the Mental Health Act. Br J Psychiatry 2002 180: 198-199

6. Singh SP, Burns T. Race and mental health: there is more to race than racism. BMJ 2006: 333: 648-651

7. Department of Health. Delivering Race Equality in Mental Health Care. London Department of Health, 2005

8. Healthcare Commission. Count Me In: Results of the National Census of Inpatients in Mental Health Hospitals and Facilities in England and Wales. London: Healthcare Commission, 2005. (Note: a further report was issued in 2006.) 